\title{
CRIME RISKS AND RURAL ROUTINES: A THEORETICAL EXAMINATION OF GUARDIANSHIP ACTIVITIES IN RURAL AREAS
}

Meghan E. Hollis, Ph.D.

Research Scholar

Ronin Institute for Independent Scholarship

127 Haddon Place

Montclair, New Jersey 07043

Shannon Hankhouse, Ed.D.

Assistant Professor

1400 College Drive

Tarleton State University

Waco, Texas 76708

Contact: Meghan E. Hollis: +1 617633 4487; drmehollis@gmail.com

\begin{abstract}
There is a considerable and growing literature on routine activities theory (Cohen and Felson, 1979) and, more specifically, the guardianship component of the theory (e.g., Reynald, 2009; 2010). Much of this literature is focused on urban and suburban contexts. The current paper examines the theoretical application of the guardianship concept in rural contexts. Given the different structures of daily routine activities, travel patterns, and other aspects of rural living, the manner in which guardianship works is likely to differ in rural contexts. Recommendations for theory and future research are discussed.
\end{abstract}

Keywords: rural communities, routine activities theory, guardianship 


\section{Introduction}

Criminological theory and research face a significant challenge in the United States and abroad in that most theoretical tests focus on highly urbanized or (perhaps) suburban communities, and most theories have been developed based on observations of and studies in urban areas. It is important to examine our current theoretical literature to determine if the same theories apply to other contexts (i.e., suburban, exurban, rural). An examination of the major theoretical work and research related to routine activity theory (Cohen and Felson, 1979) indicates that this theory has been developed and tested based on observations of urban and suburban activity patterns. This raises concerns about whether this theory is suited to rural contexts.

Routine activity theory (Cohen and Felson, 1979) was originally conceptualized to better understand how social changes in urbanized areas were impacting changing crime rates. Items of interest included increased suburbanization, increased involvement of women in the work force, the emergence of commuter or "bedroom" communities, and changes to the size, portability, and value of consumer goods. The increase in value of consumer goods and decreased size and weight of these items occurred in social conditions where individuals were less available to act as guardians over those goods (and over their homes) resulting in higher crime rates in urban areas. The use of suburban and urban contexts to build the theory resulted in limited generalizability, however. Unlike the suburban and urban areas used to develop the original theory, rural areas have different characteristics that shape the routine activity patterns of residents. For example, individuals who are living on family farms or ranches are not likely to leave their properties for extended periods during the day. Additionally, the types, sizes, and values of consumer and other goods (e.g., tractors and other farm equipment) prevalent in rural areas likely change the nature of rural crimes. Understanding the differences in common activity patterns in rural, suburban, and urban areas is essential to determining if routine activity theory continues to apply to the rural context.

The purpose of the current paper is to examine and then expand on our understanding of routine activity theory within the rural context (Cohen and Felson, 1979) with a focus on the guardianship component of the theory. This theoretical elaboration is designed to examine ways that the guardianship construct remains consistent in urban, suburban, and rural contexts as well as areas where researchers and theorists might expect changes as we shift from activity patterns in the urban context to activity patterns in the rural context. This will increase our understanding of the generalizability of routine activity theory across divergent contexts.

\section{Routine Activity Theory: An Overview}

Routine activity theory focuses on social changes in urban areas occurring mid- $20^{\text {th }}$ century in the United States (Cohen and Felson, 1979). The theory posits that for a crime to occur, three essential elements must converge in time and space: (1) a motivated or likely offender, (2) the presence of a suitable target or targets, and (3) an absence or lack of capable guardianship 


\section{Crime Risks and Rural Routines: A Theoretical Examination of Guardianship Activities in Rural Areas - Hollis and Hankhouse}

(Cohen and Felson, 1979). While much of the focus in routine activity theory research has been limited to these three constructs, it is important to remember the original conceptualization of 'routine activities' as it applies in the current examination. Cohen and Felson (1979, p. 593) define routine activities as "recurrent and prevalent activities which provide for basic population and individual needs, whatever their biological or cultural origins." These are the activities that develop as a result of an individual's daily routine and behavioral patterns. Understanding how these routine activity patterns differ from one type of place to the next could be informative in theoretical development and refinement. In the context of rural criminology, it is important to consider unique cultural characteristics that can contribute to activity pattern differences that change how routine activities pattern crime.

In the original conceptualization of the theory, Cohen and Felson (1979, p. 588) indicate: "Rather than emphasizing the characteristics of offenders" they would "concentrate upon the circumstances in which they carry out predatory criminal acts." A key question is: Do these circumstances differ based on situational contingencies of rural, urban, suburban, and exurban communities. The current paper focuses on guardianship activities in the rural context to better understand how situational contingencies impact the routine activities that influence the presence and activities of capable guardians.

\section{The Capable Guardian}

Felson (1995, p. 53) describes guardianship as being exercised by those who serve "by simple presence to prevent crime and by absence to make crime more likely." The mechanism that allows guardianship to operate is when there is an elevated risk of detection and potential punishment or sanction for untoward behaviors as a result of a feeling that someone who could take notice and observe inappropriate behaviors is watching. Hollis et al. (2013) state "the prime guardians in society are people whose presence, proximity, and absence make it harder or easier to carry out criminal acts" (p. 67) and define guardianship as "the presence of a human element which acts - whether intentionally or not - to deter the would-be offender from committing a crime against an available target" (p. 76). Guardianship is grounded in the presence of human beings who deter crime through the potential for detection by those who might intervene. Guardianship relies on the offender's ability to read a social situation and determine whether or not they will be observed in the commission of an inappropriate act, and whether or not being observed by others will result in punitive action or negative intervention.

As mentioned previously, the focus of the original work (Cohen and Felson, 1979) was on changes to urban contexts (or socio-demographic changes in major cities). The original theorists indicated that changes to the routine activities that structure everyday life also impact criminal opportunity structures. With respect to guardianship, Cohen and Felson (1979, p. 590) indicate: "Though guardianship is implicit in everyday life, it usually is marked by the absence of violations; hence it is easy to overlook." It is important to examine how the rhythms of daily life in rural areas can influence guardianship potential in deterring rural crimes. While urban areas 
are characterized by activity patterns dominated by travel between residences, work, school, entertainment venues, shopping, and other common activity nodes, the parallel activity patterns in rural contexts are not clear and require further study and elaboration.

\section{Development of the Guardianship Construct}

The guardianship construct is not fully developed until later work (e.g., Reynald, 2009; 2010; Hollis-Peel and Welsh, 2014; Hollis, et al., 2015). For example, the guardianship construct was eventually expanded to include handlers, guardians, and place managers. Handlers are those people who keep "an eye on the potential offender" (Felson, 2006: p. 80). These include individuals such as parents who look after children, teachers who look after students, and employers who look after employees. The key here is that the handler watches individuals who are likely to commit criminal or deviant acts absent that supervision and monitoring.

Target guardians are those individuals who keep "an eye on the potential target of crime" (Felson, 2006: p. 80). These tend to be more fluid and include those individuals who are present and able to observe potential targets for criminal activity. In the rural context, this could include barn managers, farm hands, or stable employees who are present and watching over the potential targets for criminal activity. For example, farm and barn employees who live on the property are available and able to detect the would-be offender who wants to steal farm equipment or livestock.

Place managers look after places to prevent criminal activity in specific locations (Felson, 2006). These are individuals who are tasked with watching specific places to deter would-be offenders, such as security guards. In the rural context these could include individuals tasked with security functions on corporate farms. Felson (2006) states: "In general, a crime is unlikely if a handler is supervising the likely offender, a guardian is watching the target, and a manager keeps track of the place" (p. 81). While Felson indicates that "Some metropolitan spaces and places are largely devoid of guardians, handlers, and place managers, and are thus quite suitable for setting up crime" (p. 85), the influence and activities of guardians outside of the metropolitan context are not addressed.

\section{Introduction of the Guardianship in Action Construct}

Recent research has introduced an action-based, direct observational method to study guardianship activities. The Guardianship in Action (GIA) concept introduced by Reynald (2009; 2010) provides a more nuanced description and understanding of guardianship. Reynald (2009; 2010) broke guardianship down into active stages that could be directly observed.

The first stage of observed guardianship described in this work is invisibility (Reynald, $2009 ; 2010)$. This occurs where guardians are not available, and no potential guardians are observed by the motivated offender. The second stage of guardianship in action is availability (Reynald, 2009; 2010). This is where there is someone present who could observe the behavior. This is the simple presence of individuals who have the potential to detect untoward behaviors. 


\section{Crime Risks and Rural Routines: A Theoretical Examination of Guardianship Activities in Rural Areas - Hollis and Hankhouse}

The third stage of guardianship in action is capability (Reynald, 2009; 2010). This exists where guardians are present who could observe untoward behaviors, but they are also monitoring their surroundings. The best example of this is the "nosy neighbor" looking out of their windows and keeping tabs on the events occurring in their local neighborhood. These individuals are actively monitoring their surroundings and, thus, increase the likelihood that they will detect criminal or deviant behaviors.

The final stage of guardianship in action is the intervening stage (Reynald, 2009; 2010). This is where the capable guardian goes beyond monitoring their surroundings to intervene with individuals who are suspected of untoward behavior or who seem out of place. Reynald (2009; 2010) studied direct intervention where the guardian approaches the potential offender or suspicious person to ask what they are doing and/or to make an effort to stop their behaviors. Hollis-Peel and Welsh (2014) expanded the intervention construct to include both direct and indirect guardian interventions. Indirect intervention occurs where the guardian calls the police, security, or some other third party to intervene on their behalf (Hollis-Peel and Welsh, 2014). As seen here, research on guardianship has transformed from proxy-based measures to direct observation based on these changes in conceptualization of the guardianship construct. This progression toward action-based guardianship observation has enhanced our understanding of the underling theoretical mechanisms that allow guardianship to operate.

\section{Existing Research on Guardianship and Routine Activities Theory}

Routine activity theory (Cohen and Felson, 1979), a rational choice perspective, has been the focus of much research over the past four decades. Early theoretical work focused on social structural changes and macro-structural tests of the theory (see, e.g., Bennett, 1991). Recent research has included theoretical tests using national survey data, field observations, crossnational comparisons, and experiments (see, e.g., Bennett, 1991; Reynald, 2010; Hollis-Peel, et al., 2011). Of the three elements of the theory, offender motivation is typically assumed in theoretical tests. Routine activity theory leaves the explanation of why offenders commit crimes to other theorists and assumes that given the right situational contingencies anyone can become a motivated offender. Most research, therefore, focuses on target suitability. This is, perhaps, because this is the easiest of the three elements to study. However, more recent work has been dedicated to better understanding the guardianship construct (e.g., Hollis-Peel et al, 2011; Reynald, 2009; 2010).

Early guardianship research focused on proxy indicators of guardianship, such as police employment and expenditure (Stahura and Sloan, 1988), female labor force non-participation (Stahura and Sloan, 1988), household occupancy (Miethe et al., 1990), living with another householder (Miethe and Meier, 1994), or presence of a dog or alarm system (Garofalo and Clark, 1992). Additional approaches utilized self-protective or target-hardening measures (Mustaine and Tewksbury, 1998; Tewksbury and Mustaine, 2003; and Coupe and Blake, 2006). In early guardianship research, it was common to measure guardianship using data on female 
labor force participation (Bennett, 1991); prevention measures combined with single parenthood (Tseloni, et al., 2004); individual-level target hardening, place management, and/or surveillance measures (Wilcox et al., 2007); and homes with "homemakers" present (Tseloni, et al., 2004). Hollis-Peel et al. (2011) critique these measures as they confuse the target hardening and target suitability components of the theory with guardianship components (highlighting the need for better measurement and definitional processes) and involve proxy measures that do not accurately assess the presence or absence of guardianship at the time of a criminal event.

Recent research has moved away from these proxy measures of guardianship to focus on action-based measurement of guardianship - observation of behaviors and activities rather than reported attitudes from surveys or proxy measures from census data as discussed in the previous section. Reynald $(2009,2010)$ pioneered this approach measuring guardianship through direct observation and field data collection in The Netherlands. This guardianship in action approach has been successfully replicated in the United States (Hollis-Peel and Welsh, 2014). This approach improves on the previously discussed proxy measures to allow closer approximation of the guardianship construct in research.

Guardianship in action approaches use direct field observation to assess levels and types of guardianship in local environments (Reynald, 2009; 2010). This approach involves collecting data on a variety of physical environment variables as well as directly observed guardianship. The trained observer goes to the sampled property and observes the property. The observer starts by recording information related to the physical environment variables. The observer then notes whether there is anyone home or present at the property (signs that there is someone there such as lights, a vehicle in the driveway, movement in the home, etc.), whether there is anyone monitoring their surroundings (looking out the window, watching the observer, etc.), and whether or not anyone intervenes during the observation (perhaps by confronting the observer to ask what they are doing there). These are then used to assess the level of guardianship at the property observed. Additional information is collected on the traffic patterns (foot, bicycle, and vehicular) on the observed street segment. Research evidence has demonstrated that this tool provides a valid measure of guardianship in community contexts.

Clearly there is a growing body of research on the guardianship dimension of routine activity theory. Despite this increased interest in guardianship research, one area remains relatively unexplored in the research literature: How does guardianship operate in rural contexts? Are there distinctive patterns that we need to understand in order to apply Routine Activities Theory to the study of rural crime? The remaining sections of this paper seek to elaborate on guardianship in rural contexts. 


\section{Crime Risks and Rural Routines: A Theoretical Examination of Guardianship Activities in Rural Areas - Hollis and Hankhouse}

\section{Research Examining Guardianship and Routine Activities Theory in the Rural Context}

To date, research regarding routine activities theory and guardianship has been predominately focused on urban areas. In previous research, the definition of rural areas is regularly comprised of three main components: a more communal or cohesive lifestyle, economies more reliant on extractive industries (agricultural, wildlife, fishing, mining, and forestry), and with smaller populations and lower population density (Mawby, 2015). Based on existing research, guardianship levels in rural contexts can be differentiated into three main categories: social (self, neighborhood watch groups, parental supervision), technological (alarm systems, security lighting), and formal policing (Mawby, 2015; Spano and Nagy, 2005). Some of these measures are at odds with the preferred definition of guardianship that differentiates it from target hardening (where alarm systems and security systems would be classified as target hardening efforts rather than guardianship). Furthermore, the focus of guardianship research should be on informal guardianship by citizens going through the routine activities of their dayto-day lives, rather than the presence of formal police. All previously used conceptualizations of guardianship will be discussed, but the remaining sections will focus on the influence of informal guardianship modalities.

\section{Formal Guardianship in Rural Contexts}

Formal guardianship by police in rural areas has been decidedly marked by a lower police presence. The decreased police presence in rural areas is due the ratio of law enforcement personnel to population and increased geographical areas of patrol. Complicated by ambiguous jurisdictional lines and an increased variety of calls for service, policing in rural areas can be more difficult than policing in urban areas (McCleary, 2008; Mawby, 2015). Of course, this should not be the focal concern of guardianship research as it is the presence of ordinary citizens that forms the basis for most guardianship activity (as mentioned previously).

\section{Technological Guardianship in Rural Contexts}

Prior research has also examined technological dimensions of guardianship in rural settings (Mawby, 2015; Spano and Nagy, 2005). These studies have examined tools, such as security cameras, security lighting, and other similar technologies used to increase self-protection. Two conceptualizations of technologies (including both electronic and non-electronic technologies) and tools are useful in this context. First, these additional tools can be seen as target hardening measures intended to make it more difficult to victimize the given target. This might be the case when considering tools such as electrified or barbed wire fencing around a property.

On the other hand, these tools can be seen as tools used to enhance guardianship. These would include tools that are used to enhance the existing guardians' capacity to engage in guardianship activities. For example, security cameras could be used on larger properties (such as farms and ranches) to expand the views of active guardians allowing them to detect inappropriate activities over more area. Enhanced security lighting could be used to make it 
easier to see the would-be offenders as they enter the property, again enhancing the capacity to engage in guardianship activities. Similarly, the presence of a dog could serve as a guardianship enhancer because a barking dog alerts the human guardians to the presence of the potential offender. It is important to note that these tools are not guardianship without introducing the human component. It is the human component that allows monitoring and detection of behaviors.

\section{Social Guardianship in Rural Contexts}

The form of guardianship discussed in previous rural criminology literature that is the closest to the definition used here is social guardianship. This form of guardianship highlights the informal activities of other human beings that could serve to deter the would-be offender through presence alone. The remaining sections of this paper are devoted to examining this form of guardianship.

The impact of guardianship on rural crime requires further research; however, one study showed that in the rural context residents who spent more time away from home during the day and most evenings experienced more crime than residents who spent less time out of their homes (Mawby and Jones, 2004). ${ }^{1}$ Furthermore, Mawby and Jones (2005, p.119) suggest that the remoteness of residential areas does not equate to low risk of crime and further indicate that "informal surveillance by neighbors or passersby may impact crime, at least as far as more planned offending is concerned". Similarly, Mears et al. (2007) found that in rural areas guardianship is the most consistent predictor of rural crime victimization, specifically agricultural crimes. Unfortunately, the methods of measuring guardianship in these studies are typically based on proxy measures rather than direct observation of guardianship based in routine daily activity patterns of rural residents.

In summary, current routine activities theory and guardianship research is focused on urban and suburban contexts. Additionally, much of this research focuses on guardianship in residential neighborhoods in these contexts. Research examining guardianship outside of residential contexts and in rural areas has been largely nonexistent to date. The next section expands on how controller/guardian routine activities are likely to differ in rural contexts when compared to urban contexts.

\section{Rural Guardianship: Controllers}

Another means of examining guardianship in rural contexts is to examine the role of different types of controller guardians as discussed in Eck (1994) and Felson (1995). As discussed previously, these include handlers, place managers, and target guardians. The routine activities of these different controller types influence their role in reducing crime in rural areas. 


\section{Crime Risks and Rural Routines: A Theoretical Examination of Guardianship Activities in Rural Areas - Hollis and Hankhouse}

\section{Handlers}

Handlers are those individuals who watch potentially motivated offenders. These individuals can include parents, school teachers, babysitters, and employers/supervisors. In rural environments, handlers continue to take on a similar role to what would be seen in the urban or suburban environment. The key differences emerge in the routine activities of the handlers. There are a variety of influences on the role of the handler in the rural context including: the employment-related routine activities of the handler (e.g., parents running family farms, commuting into a nearby city for employment, working from home, homemaker, or some other employment-related routine activity). Differences in employment-related routine activities could have important effects on the ability of handlers to monitor the behaviors of potential offenders. This warrants further study through surveys of rural residents to assess their common daily routines.

\section{Place Managers}

As mentioned previously, place managers are those individuals who look after places where crimes are likely to occur. These individuals do not have to have a formal responsibility for looking after the place, but through their presence and availability alone are able to deter potential offenders by watching a place. For example, in the rural context place managers are less likely to be formal security guards (as is often the case in urban areas), but there is still potential for other types of place managers. On farm or ranch properties, for example, you might have ranch hands, farm hands, barn managers, and others who are responsible for looking after the property, even though they are not formal security guards.

Additionally, areas with corporate farms, farming research laboratories, and other similar locations could have formal security guards on the property. Some rural properties take the additional step of having a limited entry/access-control gate, and these sometimes have security cameras allowing the property owner or employees to monitor those who enter or attempt to enter the property. These cameras can be monitored remotely (allowing individuals who do not maintain their rural property as their primary residence to monitor those who enter the property remotely via a smart phone or computer).

\section{Target Guardians}

The final controller is the target guardian. As discussed previously, these are individuals who look after potential targets of criminal activity. These individuals are not necessarily tasked with looking after crime targets, but it is through their presence and potential to see the motivated offender victimize the target that they deter criminal activity. These can be residents, employees, or others in rural areas who through their presence alone deter the potential offender.

An interesting challenge in rural areas relates to limitations on the number of capable guardians who are available to monitor their surroundings. Rural areas include larger 
geographical areas with significantly lower population densities when compared to urban or suburban areas. This limits the number of people available to monitor potential crime targets and creates challenges for crime prevention strategies. Additionally, routine activity patterns of rural residents could create opportunities for criminal activity. The geographic and physical design features of rural properties as they influence crime opportunities and opportunities for capable guardianship warrant further consideration.

\section{Guardianship and Geographic and Physical Design Characteristics of Rural Areas}

The rural context creates different situational contingencies for criminal activity as well as the ability of guardians to engage in guardianship activities. These situational contingencies are based on differential routine activity patterns of residents and others in rural spaces as well as differences in the physical design, layout, and common land uses present in rural areas. It is essential to theorize about how differences in common daily routine activity patterns might manifest in influencing guardianship activities (and, therefore, criminal activity patterns) in the rural context.

\section{Individual Routine Activity Patterns}

Common activity patterns in rural areas can differ in significant ways from those in urban and suburban areas; however, there are also some common themes. Common daily routine activities for residents in all three types of communities include: residence (where we sleep, eat, rest, and live), work or employment (where we carry out our job functions), entertainment (where we go to have fun or relax), and shopping (where we go to purchase things we need or want). Key differences emerge when comparing urban and rural routine activities as there are a wider array of potential patterns available to rural residents. For example, while there are people in rural areas who live on their residential property in the rural area but commute to an urban center for work, there are also individuals who live and work in the same place (as is seen on family farms and ranches). Entertainment venues could take rural residents away from their homes and into local cities and towns, but sometimes rural areas provide entertainment venues as well. For example, ranches and farms might provide entertainment for urban residents who travel to the country to ride horses, hike, or go fishing.

These different behavior and activity patterns, in turn, can contribute to challenges in developing and/or maintaining active guardianship in rural areas. Owners of family farms might be forced to work additional jobs to make ends meet. This could create activity patterns whereby the farm is unattended and there is no guardianship for extended periods of time. Alternately, they could be in the field for extended periods of time leaving the primary residence vacant and unguarded. Corporate farms may have more security mechanisms than smaller family-owned farms, but they could also be more likely to be subject to corporate espionage efforts. Additionally, there might not be a primary residence on a corporate farm indicating that the farm 


\section{Crime Risks and Rural Routines: A Theoretical Examination of Guardianship Activities in Rural Areas - Hollis and Hankhouse}

might be left unattended outside of normal working hours. Ranches, deer leases, and weekend or vacation properties might be left unattended for days, weeks, or months at a time. Residential properties may be left vacant as residents travel into local towns and cities to work for the day. All these factors enhance the challenges in studying and understanding guardianship in rural areas. It is essential that rural criminology research examine the routine activity structures in place to better understand how these activity patterns might shape potential guardianship capacity in the rural environment.

The variability in land uses and types of common activities creates challenges in studying common individual routine activities in rural areas. Perhaps the most striking feature is that there is no common element in the way space is used across rural areas. This requires consideration of how land uses, traffic patterns, and the geospatial distribution of people influences routine activities and guardianship potential in rural areas.

\section{Spatial Distribution of Land Uses}

The spatial distribution and spatial patterning of land uses has an important impact on the presence and activities of capable guardians. The first area of concern relates to how proximity might impact the presence of capable guardians. Homes and properties in rural areas are more distant than those in suburban or urban areas. In some instances, it might not be possible to see the neighboring properties and they might even be miles apart. This distance from neighbors makes guardianship as conceptualized previously not an appropriate mechanism for preventing criminal activity. This distance can impact the likelihood and frequency of communications between neighbors. Although the increased use of cell phones, telephones, texting, and internet technologies such as Facebook ${ }^{\circledR}$ might make this communication less challenging, those types of exchanges would not be observed by the would-be offender and, therefore, would not serve a deterrent purpose. If an offender is scouting one's property and the offender cannot see the neighbors from the property under surveillance, the neighbors also are not likely to have a guardian effect on the offender. This raises important questions about how to demonstrate that potential guardians are present in rural areas.

In addition to increased distances between properties and residences that might limit the ability of neighbors to observe inappropriate or untoward behaviors on neighboring properties, the distance of properties from the road can also present a guardianship challenge. In rural areas, properties can be set back from the road (sometimes down a lengthy private drive or dirt road). These properties might have a lot of tree cover that inhibits the ability to see the road from the property and the property from the road. While there may be traffic on these roads, it is often at higher speeds and may often include individuals who are not paying attention to activities in their surroundings. The neighbor, police officer, or other individuals driving by a rural property that is set back from the road might not be able to observe inappropriate activities occurring there. This could reduce the ability of guardianship activities to influence that property since 
potential offenders cannot observe and, thus, be deterred by the capable guardian. In guardianship in action terms, there are no guardians visible (and we are at the invisibility stage).

The design of properties could include multiple buildings, and it might not be easy to see all the property from the residence or from other buildings. Again, this can further limit guardianship potential by increasing the difficulty for guardians to monitor the full property. Urban areas are often characterized by smaller parcels where it is easier to see the full property at any time (or most of the property). Rural parcels often cover larger geographic spaces limiting the ability to fully monitor the property. Tools of guardianship such as security cameras that are easily monitored (or where they can be monitored via portable equipment such as a smart phone) and motion detectors can assist the rural property owner in these situations.

\section{Types of Properties and Land Uses}

The types of buildings on a property and the distance of the buildings from the main property provide another challenge for active guardianship in rural areas. Urban and suburban areas are more likely to have a single residential property (perhaps with a shed and/or detached garage), while rural areas might have multiple buildings away from the main residence. The types and number of buildings often vary dramatically from one property to another but might include a barn (or multiple barns) designed to house animals and equipment, smaller buildings such as chicken coops and sheds, grazing pastures, silos, other storage buildings or warehouses for farm equipment, stables, and any number of other types of buildings. Properties vary in type including: rural residences, family farms, ranches, deer leases, country and feed stores, training facilities, storage facilities, state parks, corporate farms, and many other land uses.

There are a variety of types of properties in rural areas. This can further complicate the types of guardianship activities that might be expected in a given area. Rural areas might include ranch properties, farms, private residences, weekend or vacation homes, properties used for hunting and fishing, businesses, tack and feed stores, country stores, stables, and other property types. Ranch properties can be ranches that are used for livestock production or the alternate ranch of the wealthy landowner (that may or may not be used for livestock but can also be a large land area and residence used as a vacation property or weekend retreat). Farms can be private family-owned farms or large corporate farms. Rural areas are also often homes to correctional facilities. The variety of property types can create challenges in crime prevention efforts. For example, the local farmers might be willing to look out for each other's properties but might not have the means to do so as their time is spent looking after their own properties, crops, and livestock or they are unable to see neighboring properties. The wide array of property types can have an impact on the daily routine activities expected in these areas. This, in turn, can have an impact on the availability and capability of guardians on any given day.

Each of the types of buildings have varying levels of security (or ability to secure) and create opportunities for different crime types than are seen in urban and suburban areas. The variety of building types and ability to observe behaviors in or around those properties (or from 


\section{Crime Risks and Rural Routines: A Theoretical Examination of Guardianship Activities in Rural Areas - Hollis and Hankhouse}

those properties) can have an influence on guardianship capacity. For example, an individual working in a barn with no or few windows is less likely to observe the potential offender approaching the residential property nearby (or targeting other buildings on the parcel that are out of view or hearing of the barn). This differential structure of the environment could have important implications for the structure of routine activities as it relates to capacity for guardianship. In other words, property owners need to consider what steps they can take to create the sense that a person is being watched on their property when there are not as many people around to engage in guardianship activities.

It is important to note that different physical and environmental structure that exists in rural areas can create opportunities for crimes not seen in urban and suburban areas. These different crime types can create different types of guardianship requirements. Accessibility of silos and other food storage facilities can create opportunities for theft of crops and/or poisoning/tampering with crops. Opportunities for targeting crops as they grow in the field are also a concern. It is not easy to secure fields of crops that cover multiple acres to protect them from a motivated offender. As such, guardianship over crops can present an interesting challenge. It is not possible for the farmer, their family, or (if they have employees) their staff to keep a constant vigil on the crops at all stages of production. This raises important questions as to how to maintain guardianship over vulnerable crops targeted for crimes. Further research is required to better understand the prevalence of these types of crimes in rural areas. Reporting rates of these types of crimes also need to be studied.

\section{Available Targets and Guardianship}

The types of targets of criminal activity that are available in rural areas also shifts the way that guardianship operates. For example, concerns emerge related to poaching, poisoning, or otherwise targeting livestock and crops. Heavy machinery and farm equipment is also vulnerable in rural areas for both tampering and theft (or theft of parts). It is not always possible to secure livestock when they are in barns and other structures. These challenges are exacerbated when livestock are "let out to pasture". For example, cattle on ranches are often not under constant supervision by ranchers or ranch hands. These concerns are exacerbated, because guardianship in areas with higher volumes of land to monitor is limited. This can create challenges in using active guardianship strategies to prevent criminal victimization in these areas. While in some instances, cattle on the range are supervised by ranch hands that supervise and care for the livestock, in most instances this is not the case (gone are the days of cowboys watching the herd

for weeks at a time on the open range). Additionally, important questions arise about the level of guardianship when livestock are secured or housed in barns and other structures. This requires consideration of a variety of tools that can be used to enhance guardianship capacity in these areas.

The types of targets available for theft include traditional household items in rural residences, but also include many targets not seen in urban or suburban areas. Machinery can 
include bulky items like tractors (including garden tractors) and combines or smaller items such as four wheelers, tools, and accessories for larger equipment. Additionally, these larger items can be targeted for theft of parts. Many of these items are worth high dollar amounts making them potentially lucrative targets for theft. Farm equipment such as tractors and combines can also become targets for vandalism, property damage, or joy-riding. Many times there are not adequate storage facilities for this equipment where tools and equipment can be secured inside a structure (such as a garage, barn, or shed), and they are left in the open. On properties housing horses, tack rooms can be targeted for expensive horseback riding equipment. Saddles, bridles, bits, stirrups, and other riding equipment can be extremely expensive (often made of high quality French leather). These materials are not always properly secured in a locked tack room or shed. The different types of targets combined with the storage and availability of these targets raises additional questions regarding how guardianship over these targets might operate in practice.

Additional crime targets come in the form of animals on the property. Cattle and horses can be of extremely high value. They can become targets for theft, animal cruelty and abuse, creating false documents related to sales and purchase of animals, cattle rustling, cattle and other animal poisoning, and cattle and other animal shooting/killing. Consider the value of racing horses and show horses combined with the competitive nature of equine sports, and the potential for criminal targeting is high.

Additional disparities between rural and urban/suburban areas relate to differences in traffic patterns. Rural roads are not traveled by the volume of individuals that frequent urban and suburban roads. This simultaneously decreases the likelihood that a rural place will be a part of a motivated offender's activity and/or awareness space and decreases the presence of capable guardians. This could also contribute to decreased anonymity as residents of localized areas in rural contexts are more likely to know the people around them and those expected to be in the area. As a result they may be more wary of outsiders when their presence is noticed. Furthermore, the local speed limits and accessibility of roads (such as considerations of the type of road - state highway, country road, rural route, etc.) can have an impact on activity patterns and whether a given area becomes a part of a motivated offender's routine activity space. This warrants further examination to determine the impact of road structures on the types and volumes of crimes committed in rural contexts.

\section{Traffic Patterns and Travel Paths}

Another key consideration relates to access to and travel paths to and from rural locations. The ease of access in rural areas may be decreased, and this can result in difficulty finding suitable targets and quick escape pathways for motivated offenders. This difficulty could make it more likely that a person will be noticed by a guardian on their way to or from the "scene" of the crime. A motivated offender who is unsure of their entrance and exit paths on the way to and from the commission of a crime is more likely to be noticed as their behavioral patterns are likely to reflect the lack of familiarity with the local area. 


\section{Crime Risks and Rural Routines: A Theoretical Examination of Guardianship Activities in Rural Areas - Hollis and Hankhouse}

At the same time, there are more opportunities for the motivated offender to escape detection in rural areas. Law enforcement officers called to respond to crimes in these areas might have more difficulty locating the property, and they will take more time to arrive at the scene of a crime. This creates a condition where the motivated offender could have more time to get away after the commission of a crime, even when that crime is detected. On the other hand, capable guardians in these areas may be more likely to carry firearms. In states with "stand your ground" laws, this could increase the deterrent potential of guardians as motivated offenders may be concerned about being shot during the commission of their crimes. This could mitigate the response time challenges. These unique features of rural areas warrant further research.

Research needs to examine the design of rural roads to better understand accessibility and ease of entrance and exit of these areas. This might indicate that rural crimes are more likely to be committed by those living in the rural areas. Additionally, research needs to examine the influence of "stand your ground" laws, police patrol capabilities, and response times in rural areas. There are important implications arising from these important areas of research.

\section{Discussion and Conclusion}

Ultimately, it is essential to evaluate if guardianship operates in the same manner in rural contexts, as it does in urban and suburban contexts. It is likely that the difference in the types of crimes likely merge with the different types of available targets and properties and the disparate activity patterns (including travel paths) in rural areas to produce a different routine activity patterns that influence guardianship capabilities. Guardianship availability in rural areas is likely different than guardianship in urban and suburban settings as a result of the differences in geospatial, land use, and social activity structures.

Rural areas have a lower population density over a larger geographic area. While this may mean fewer motivated offenders, it also means that there is a decrease in individuals available to act as capable guardians. Additionally, the activities common to rural areas can change routine activity patterns and also change the typical guardianship activities that might be observed. It is far less likely that there will be distinct entertainment districts, educational/school zones, shopping districts, residential neighborhoods, and so forth, in rural areas. These lines are blurred with homes often occupying the same land as farm land, entertainment venues, shopping areas, and other land uses. Absent a cluster of residential homes in a defined neighborhood, how does guardianship operate? Since most studies of guardianship to date have focused on residential areas, this is an important research question to address in future research. 


\section{Recommendations for Theoretical Refinement and Future Research}

The analysis of the application of routine activities theory (with a focus on guardianship) in rural contexts in this paper has provided important guidance for future rural criminology scholars. An essential aspect routine activities research that remains underdeveloped is an understanding of how social changes in rural areas over previous (and recent) decades have changed the structure of routine activities in rural areas. While there is a large volume of research on routine activity and behavior patterns in urban and suburban settings, rural areas have been largely ignored. An examination of the impact of social changes to rural areas over time would provide an informative lens into changing rural crime patterns. While this research would largely rely on proxy measures similar to those used in the original Cohen and Felson (1979) routine activity theory study, this research would make an important contribution to the rural criminology literature.

Expanding on this, future research needs to examine common routine activity patterns in rural areas. A key research question that should be addressed is: What are the common routine activity patterns in rural areas? This should include a detailed examination and analysis of how routine activities in rural areas are different from those in urban, suburban, or exurban areas. Researchers need to work to understand what shapes those routine activity patterns and how the differential situational contingencies can feed variations in crime rates and types of crimes observed in rural areas. While we know that crime is not equally distributed across urban and suburban spaces, it is important to examine the degree to which this observation holds in rural areas as well. This requires an examination of how the physical design and structure of rural spaces influences activity patterns related to crime.

Research should focus on examining observational guardianship in rural areas. This includes replications of Reynald's $(2009 ; 2010)$ work in rural areas. An effort is currently underway to examine guardianship in action in Waco, Texas and the surrounding rural incorporated and unincorporated areas of McLennan County, Texas. Additional efforts should collect data on areas more removed from major cities and highways (Interstate 35, which connects San Antonio to Austin to the Dallas-Fort Worth metroplex, runs through McLennan County) to further explore variations across different types of rural areas. Additionally, guardianship research in rural contexts should work to examine the presence and activity patterns of controllers broken down into guardians who look after targets, handlers who look after potential offenders, and managers who look after places in the rural context. An important question relates to whether these three primary types of controller/guardians continue to apply in this context. Observational studies could provide useful information on the types of controllers and how they operate in rural space. 


\section{Crime Risks and Rural Routines: A Theoretical Examination of Guardianship Activities in Rural Areas - Hollis and Hankhouse}

\section{Final Remarks}

This paper presented an overview and conceptual examination of guardianship in rural contexts. It is essential that future guardianship and routine activities research examines these constructs in rural settings to better understand how guardianship operates in the rural context. Future researchers should work to gather direct observational data on guardianship in rural contexts to expand our understanding of the concept and the theory.

Research on rural guardianship and rural routine activities would be informative in developing appropriate crime prevention and response measures for rural areas. Unfortunately, not enough is known about crime in rural areas. Although this is a growing area of criminological research, much more research is needed. This paper has highlighted several areas for future scholars to explore in expanding the research literature on rural criminology. Key areas highlighted include examining how social changes have impacted crime rates in rural areas over time, developing a better understanding of routine activities in rural areas, studying how land use patterns and the spatial distributions of properties influence crime rates in rural areas, studying the prevalence and covariates of crime categories unique to rural areas, and examining how traffic patterns in rural areas influence crime patterns. These areas are worthy of future scholarship and require focused data collection efforts. Replications of the routine activities research from urban areas (such as the guardianship in action studies) would be beneficial in expanding the scholarship in this area as well.

\section{Endnote}

${ }^{1}$ These individuals may spend time out of their homes as a result of commuting to nearby cities for work, or they could spend time out of their homes tending to their land, crops, and animals (making them less available as guardians of the residential components of their properties potentially). The important thing is that some type of routine activity takes these individuals away from their homes. 


\section{References}

Bennett, R. (1991). Routine activities: A cross-national assessment of a criminological perspective. Social Forces, 70(1): 147-163. https://doi.org/10.1093/sf/70.1.147

Cohen, L.E. and Felson, M. (1979). Social change and crime rate trends: A routine activity approach. American Sociological Review, 44(4), 588-608. https://doi.org/10.2307/2094589

Coupe, T. and Blake, L. (2006). Daylight and darkness targeting strategies and the risks of being seen at residential burglaries. Criminology, 44(2), 431-464. https://doi.org/10.1111/j.1745-9125.2006.00054.x

Eck, J. (1994). Drug markets and drug places: a case-control study of the spatial structure of illicit drug dealing. Unpublished Ph.D. dissertation, College Park, MD: University of Maryland.

Felson, M. (1995). Those who discourage crime. In: J.E. Eck and D. Weisburd (eds.), Crime and Place. Vol. 4, Crime Prevention Studies. Monsey, NY: Criminal Justice Press, pp. 53-66.

Garofalo, J. and Clark, D. (1992). Guardianship and residential burglary. Justice Quarterly, 9(3), 443-463. https://doi.org/10.1080/07418829200091471

Hollis-Peel, M.E. \& Welsh, B.C. (2014). What makes a guardian capable? A test of guardianship in action. Security Journal, 27(3): 320-337.

https://doi.org/10.1057/sj.2012.32

Hollis, M.E., Felson, M., \& Welsh, B.C. (2013). The capable guardian in routine activities theory: A theoretical and conceptual reappraisal. Crime Prevention and Community Safety, 15(1): 65-79. https://doi.org/10.1057/cpcs.2012.14

Hollis-Peel, M.E., Reynald, D.M., van Bavel, M., Elffers, H., and Welsh, B.C. (2011). Guardianship for crime prevention: A critical review of the literature. Crime, Law, and Social Change, 56(1), 53-70. https://doi.org/10.1007/s10611-011-9309-2

Mawby, R. I. (2015). Exploring the relationship between crime and place in the countryside. Journal of Rural Studies, 39, 262-270. https://doi.org/10.1016/j.jrurstud.2014.12.003

Mawby, R. I., \& Jones, C. (2004). Explaining patterns of victimization within a rural county of England. International Criminal Justice Review, 14, 99-123. https://doi.org/10.1177/105756770401400105

McCleary, R. (2008, June). Rural hotspots: The case of adult business. Criminal Justice Policy Review, 19(2), 153-163. https://doi.org/10.1177/0887403408315111 


\section{Crime Risks and Rural Routines: A Theoretical Examination of Guardianship Activities in Rural Areas - Hollis and Hankhouse}

Mears, D. P., Scott, M. L., \& Bhati, A. S. (2007). Opportunity theory and agricultural crime victimization. Rural Sociology, 72(2), 151-184. https://doi.org/10.1526/003601107781170044

Miethe, T.D., and Meier, R.F. (1994). Crime and its social context: toward an integrated theory of offenders, victims and situations. Albany, NY: State University of New York Press.

Miethe, T.D., Stafford, M.C., and Sloane, D. (1990). Lifestyle changes and risks of criminal victimization. Journal of Quantitative Criminology, 6(4), 357-376. https://doi.org/10.1007/BF01066676

Mustaine, E.E. and Tewksbury, R. (1998). Predicting risks of larceny theft victimization: A routine activity analysis using refined lifestyle measures. Criminology, 36(4), 829-858. https://doi.org/10.1111/j.1745-9125.1998.tb01267.x

Reynald, D.M. (2009). Guardianship in action: Developing a new tool for measurement. Crime Prevention and Community Safety, 11(1), 1-20. https://doi.org/10.1057/cpcs.2008.19

Reynald, D.M. (2010). Guardians on guardianship: Factors affecting the willingness to supervise, the ability to detect potential offenders, and the willingness to intervene. Journal of Research in Crime and Delinquency, 47(3), 358-390. https://doi.org/10.1177/0022427810365904

Spano, R., \& Nagy, S. (2005). Social guardianship and social isolation: An application and extension of lifestyle/routine activities theory to rural adolescents. Rural Sociology, 70(3), 414-437. https://doi.org/10.1526/0036011054831189

Stahura, J.M. and Sloan, J.J. (1988). Urban stratification of places, routine activities and suburban crime rates. Social Forces, 66(4), 1102-1118. https://doi.org/10.1093/sf/66.4.1102

Tewksbury, R. and Mustaine, E.E. (2003). College students' lifestyles and self-protective behaviors: Further considerations of the guardianship concept in routine activity theory. Criminal Justice and Behavior, 30(3). 302-327. https://doi.org/10.1177/0093854803030003003

Tseloni, A., Wittebrood, K., Farrell, G., and Pease, K. (2004). Burglary victimization in England and Wales, the United States, and the Netherlands: A cross-national comparative test of routine activities and lifestyle theories. British Journal of Criminology, 44(1), 61-91. https://doi.org/10.1093/bjc/44.1.66

Wilcox, P., Madensen, T.D., and Tillyer, M.S. (2007). Guardianship in context: Implications for burglary victimization, risk and prevention. Criminology, 45(4), 771-803. https://doi.org/10.1111/j.1745-9125.2007.00094.x 